\title{
Avaliação do ciclo de vida do pavimento rígido de ciclovia: estudo de caso em Brasília
}

\begin{tabular}{c}
\hline KAROLINE MATOS DA HORA - Mestranda \\
\hline FRANCISCO JAVIER CONTRERAS PINEDA - ProfesSOR Doutor \\
\hline JOÃO HENRIQUE DA SILVA RÊGO - ProfesSOR Doutor \\
\hline CLÁUDIO HENRIQUE DE ALMEIDA F. PEREIRA - ProfeSSOR Doutor \\
\hline Programa de Pós-Graduação em Estruturas E Construção CIVIL, \\
Universidade de Brasilia - UnB
\end{tabular}

\section{RESUMO}

O USO DA BICICLETA TEM SE DESTACADO POR PROPICIAR UMA MOBILIDADE URBANA SUSTENTÁVEL. Assim, CRESce a NECESSIDADE DE INVESTIMENTOS EM INFRAESTRUTURA COM ESSE VIÉS SUSTENTÁVEL. O OBJETIVO DO TRABALHO É QUANTIFICAR OS DANOS AMBIENTAIS CAUSADOS PELOS MATERIAIS QUE COMPÕEM O PAVIMENTO RÍGIDO DAS CICLOVIAS DO DISTRITO FEDERAL E PROPOR AÇÕES PARA MITIGAR OS IMPACTOS. A METODOLOGIA FOI DIVIDIDA EM: DESCRIÇÃO DA AMOSTRA E AVALIAÇÃO DO CICLO DE VIDA (ACV). A FERRAMENTA COMPUTACIONAL UTILIZADA FOI O OPENLCA E O MÉTOdO DE ANÁLISE

\author{
ENIO PAZINI FIGUEIREDO - Doutor, Professor Titular Livre \\ Escola de Engenharia Civil e Ambiental \\ dA Universidade Federal de GoIÁs - UFG
}

Palavras-chave: ciclovia, avaliação do ciclo de vida, pavimento rígido, cimento Portland, impactos ambientais.

\section{INTRODUÇÃO}

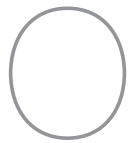

crescimento das cidades tem sido acompanhado por diversos problemas, dentre eles o transporte urbano. A crescente preocupação ambiental tem influenciado para que a sociedade busque mudanças nos seus hábitos e adote modelos de transportes mais eficientes e menos poluentes. Nesse cenário, o uso da bicicleta surge como uma opção viável do ponto de vista econômico e ambiental. Pensando nisso, os investimentos, por parte do governo, na mobilidade urbana sustentável têm aumentado com a criação e a ampliação de malhas cicloviárias por todo o país.
A ciclovia é um sistema que deve propiciar um tráfego seguro e um deslocamento mais agradável aos seus usuários. Além disso, o transporte sustentável, do qual a bicicleta faz parte, requer infraestrutura compatível que contribua para minimizar o impacto ambiental nas cidades.

Assim como os condicionantes ambientais devem ser levados em consideração desde as etapas do pré-projeto, algumas escolhas feitas durante as etapas de projeto devem ser avaliadas do ponto de vista sustentável.

O desenvolvimento de estudos relacionados à Avaliação do Ciclo de Vida (ACV) do pavimento de ciclovia poderá auxiliar na identificação de alternativas para amenizar os impactos ambientais e na criação de sistemas mais sustentáveis.

Nesse contexto, essa pesquisa tem como objetivo principal identificar e quantificar os danos ambientais causados pelos materiais que compõem o pavimento rígido da ciclovia. Com base nessa avaliação, pode-se analisar alternativas, com foco na mitigação dos impactos ambientais, para substituí-los.

\section{METODOLOGIA}

Para atender ao objetivo estabelecido, a metodologia foi dividida em duas partes: Descrição da amostra e Avaliação do Ciclo de Vida (ACV). 


\section{I Descrição da amostra}

Após definir o trecho da malha cicloviária a ser avaliado, algumas informações devem ser levantadas para a montagem do inventário e a realização das análises de ACV. São elas:

- Identificação e localização do trecho;

- Extensão, em quilômetros;

- Espessura da camada de pavimento; e

- Caracterização dos materiais e componentes do pavimento.

\subsection{Avaliação do Ciclo de Vida}

A Avaliação do Ciclo de Vida foi a ferramenta definida para auxiliar na identificação e na quantificação dos danos ambientais causados em todas as etapas do ciclo de vida da ciclovia de pavimento rígido. Ao todo, são quatro essas etapas: definição de objetivo e escopo, análise do inventário, avaliação de impacto e interpretação dos resultados [1].

A definição de objetivo e escopo corresponde à determinação do que se espera do estudo de ACV, bem como às limitações e à unidade funcional a ser utilizada.

A montagem do inventário abrange os fluxos presentes em todas as fases do ciclo de vida e requer informações reais e precisas de cada etapa e processo. De forma geral, a preferência para obtenção desses fluxos foi para os dados nacionais do Banco Nacional de Inventários do Ciclo de Vida (SICV Brasil) [2]. Caso não houvesse esses dados, foram utilizados os dados da base da Ecoinvent $v 3.6$ (2019) [3], uma das mais utilizadas e completas bases sobre o tema. O programa computacional
Tabela 1 - Categorias de impacto do CML 2001 avaliadas nessa pesquisa

\begin{tabular}{|c|c|c|}
\hline Categorias de impacto & Unidade & 0 que representam \\
\hline $\begin{array}{l}\text { Potencial de depleção abiótica } \\
\text { (ADP) }\end{array}$ & kg antimony - Eq & $\begin{array}{l}\text { Uso dos recursos não viventes (abióticos), } \\
\text { como combustíveis fósseis. }\end{array}$ \\
\hline Potencial de acidificação (AP) & $\mathrm{kg} \mathrm{SO}_{2}^{(\mathrm{a})}-\mathrm{Eq}$ & Emissões de poluentes acidificantes no ar. \\
\hline Potencial de eutrofização (EP) & $\mathrm{kg} \mathrm{PO}_{4}^{(b)}-\mathrm{Eq}$ & $\begin{array}{l}\text { Adição de altos níveis de macro } \\
\text { nutrientes, que aumentam a biomassa, } \\
\text { causando danos a outras formas de vida. }\end{array}$ \\
\hline $\begin{array}{l}\text { Potencial de ecotoxicidade } \\
\text { de águas doces (FAETP) }\end{array}$ & 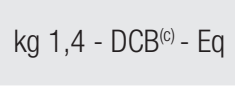 & $\begin{array}{l}\text { Grau de uma substância que induz danos } \\
\text { a organismos expostos em água doce. }\end{array}$ \\
\hline $\begin{array}{l}\text { Potencial de aquecimento } \\
\text { global (GWP) }\end{array}$ & $\mathrm{kg} \mathrm{CO}_{2}^{(\mathrm{d})}-\mathrm{Eq}$ & $\begin{array}{l}\text { Impacto sobre o aquecimento global pela } \\
\text { emissão de gases de efeito estufa. }\end{array}$ \\
\hline $\begin{array}{l}\text { Potencial de toxicidade } \\
\text { humana (HTP) }\end{array}$ & kg 1,4 - DCB - Eq & $\begin{array}{c}\text { Grau de uma substância que induz danos } \\
\text { aos seres humanos expostos. }\end{array}$ \\
\hline $\begin{array}{l}\text { Potencial de ecotoxicidade } \\
\text { de águas marinhas (MAETP) }\end{array}$ & kg 1,4 - DCB - Eq & $\begin{array}{l}\text { Grau de uma substância que induz danos } \\
\text { a organismos expostos em água marinha. }\end{array}$ \\
\hline $\begin{array}{l}\text { Potencial de depleção } \\
\text { de ozônio (ODP) }\end{array}$ & $\mathrm{kg} \mathrm{CFC}(\mathrm{e})-11-\mathrm{Eq}$ & $\begin{array}{l}\text { Perda da camada de ozônio que protege } 0 \\
\text { planeta da radiação UV nociva pelos clo- } \\
\text { rofluorcarbonos liberados na atmosfera. }\end{array}$ \\
\hline $\begin{array}{l}\text { Potencial de criação de ozônio } \\
\text { fotoquímico (POCP) }\end{array}$ & kg ethylene - Eq & $\begin{array}{c}\text { Formação de névoa fotoquímica oxidante } \\
\text { composta por poluentes em certas } \\
\text { condições meteorológicas, formando } \\
\text { ozônio na troposfera. }\end{array}$ \\
\hline $\begin{array}{l}\text { Potencial de ecotoxicidade } \\
\text { terrestre (TAETP) }\end{array}$ & kg 1,4 - DCB - Eq & $\begin{array}{c}\text { Grau de uma substância que induz danos } \\
\text { a organismos terrestres expostos. }\end{array}$ \\
\hline
\end{tabular}

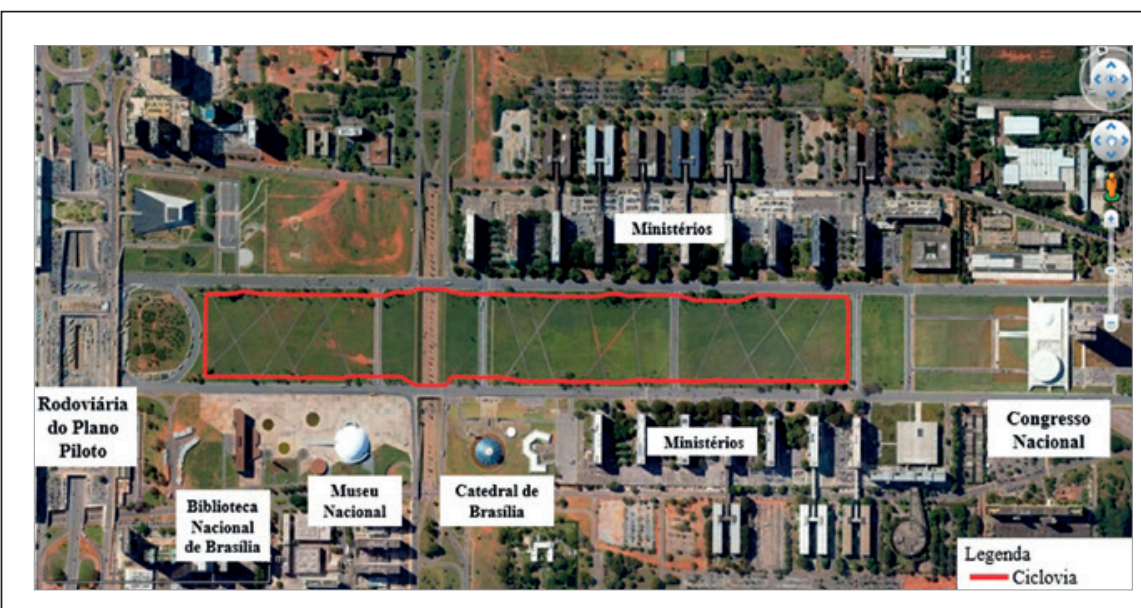

Figura 1

Imagem obtida do Google Maps da região com o segmento para avaliação selecionado da malha cicloviária, destacado em vermelho, localizado na área central da Esplanada dos Ministérios, compreendido entre a Rodoviária do Plano Piloto e o Congresso Nacional, em Brasília-DF, com a identificação das principais edificações que margeiam essa ciclovia 
selecionado para a realização deste trabalho foi o openLCA v.1.10.2 [4],

que é uma ferramenta gratuita e de fácil acesso.

\section{Tabela 2 - Informações obtidas na etapa de caracterização da amostra}

\begin{tabular}{|c|c|c|c|}
\hline Identificação e localização & Extensão & $\begin{array}{c}\text { Espessura da } \\
\text { camada de } \\
\text { pavimento }\end{array}$ & $\begin{array}{l}\text { Materiais e } \\
\text { componentes } \\
\text { do sistema }\end{array}$ \\
\hline $\begin{array}{l}\text { Ciclovia do canteiro central da Esplanada } \\
\text { dos Ministérios, área central de Brasilia-DF }\end{array}$ & $2,94 \mathrm{~km}$ & $8 \mathrm{~cm}$ & 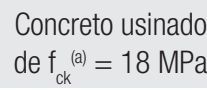 \\
\hline
\end{tabular}

Tabela 3 - Resumo do inventário para a etapa de obtenção dos materiais

\begin{tabular}{|c|c|c|c|c|}
\hline $\begin{array}{l}\text { Processo } \\
\text { principal }\end{array}$ & Tipo de Fluxo & Fluxo & Quantidade & Unidade \\
\hline \multirow{4}{*}{$\begin{array}{l}\text { Cimento } \\
(1 \mathrm{~kg}) \\
\text { CP II F-32 }\end{array}$} & \multirow{3}{*}{ Materiais } & Clínquer & 0,8654 & $\mathrm{~kg}$ \\
\hline & & Gesso & 0,0346 & $\mathrm{~kg}$ \\
\hline & & Fíler calcário & 0,1 & $\mathrm{~kg}$ \\
\hline & Energia & Eletricidade & 0,058 & kWh \\
\hline \multirow{20}{*}{$\begin{array}{l}\text { Clínquer } \\
(1 \mathrm{~kg})\end{array}$} & \multirow{4}{*}{ Materiais } & Calcário & 0,9206 & $\mathrm{~kg}$ \\
\hline & & Argila & 0,153 & $\mathrm{~kg}$ \\
\hline & & Silício & $7,20 \mathrm{E}-03$ & $\mathrm{~kg}$ \\
\hline & & Minério de ferro & $4,80 \mathrm{E}-03$ & $\mathrm{~kg}$ \\
\hline & \multirow{8}{*}{ Energia } & $\begin{array}{l}\text { Coque de petróleo } \\
\quad(33 \mathrm{MJ} / \mathrm{kg})\end{array}$ & 0,09975 & $\mathrm{~kg}$ \\
\hline & & $\begin{array}{l}\text { Carvão vegetal } \\
(31 \mathrm{MJ} / \mathrm{kg})\end{array}$ & $3,68 \mathrm{E}-03$ & $\mathrm{~kg}$ \\
\hline & & $\begin{array}{l}\text { Carvão mineral } \\
(20 \mathrm{MJ} / \mathrm{kg})\end{array}$ & $5,92 \mathrm{E}-03$ & $\mathrm{~kg}$ \\
\hline & & Lenha (15 MJ/kg) & $4,93 \mathrm{E}-03$ & $\mathrm{~kg}$ \\
\hline & & Óleo diesel & 0,0406 & MJ \\
\hline & & Gás natural $\left(36 \mathrm{MJ} / \mathrm{m}^{3}\right)$ & $7,70 \mathrm{E}-04$ & $m^{3}$ \\
\hline & & $\begin{array}{l}\text { Óleo combustível } \\
\text { (40 MJ/kg) }\end{array}$ & $3,80 \mathrm{E}-04$ & $\mathrm{~kg}$ \\
\hline & & Eletricidade & 0,058 & kWh \\
\hline & \multirow{8}{*}{ Emissões } & Dióxido de carbono & 0,9425 & $\mathrm{~kg}$ \\
\hline & & Monóxido de carbono & 0,0549 & $\mathrm{~kg}$ \\
\hline & & Óxidos de nitrogênio & $4,70 \mathrm{E}-04$ & $\mathrm{~kg}$ \\
\hline & & Metano & 0,0259 & $\mathrm{~kg}$ \\
\hline & & $\begin{array}{c}\text { Compostos orgânicos } \\
\text { voláteis não metânicos }\end{array}$ & $8,28 \mathrm{E}-03$ & $\mathrm{~kg}$ \\
\hline & & $\begin{array}{l}\text { Monóxido de } \\
\text { dinitrogênio }\end{array}$ & $2,07 E-03$ & $\mathrm{~kg}$ \\
\hline & & Partículas & $2,50 \mathrm{E}-04$ & $\mathrm{~kg}$ \\
\hline & & Óxidos de enxofre & 1,29 & $\mathrm{~kg}$ \\
\hline
\end{tabular}

Em relação a avaliação de impacto, - OpenLCA conta com uma diversidade de métodos. Dentre eles, optou-se pela metodologia CML 2001 por ter sido utilizada em trabalhos com temática semelhante $[5,6]$ e ter mostrado bons resultados. Além disso, é um método midpoint que minimiza as incertezas existentes nos fluxos adotados. Na Tabela 1 são apresentadas as categorias avaliadas pelo método CML 2001 neste trabalho, com uma breve explicação do que representam.

A última etapa do estudo de ACV é a intepretação dos resultados. Ela foi feita pela observação da contribuição de cada material da camada de pavimento da ciclovia.

\section{ESTUDO DE CASO}

A malha cicloviária do Distrito Federal é composta por $554 \mathrm{~km}$. O trecho

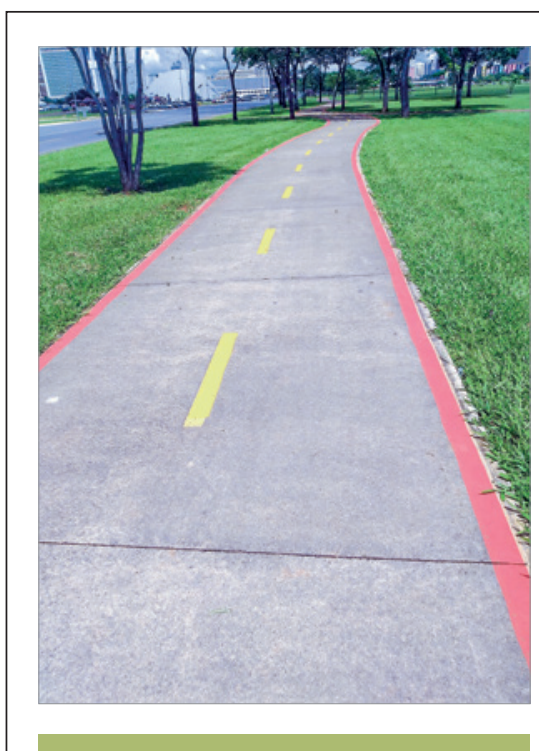

\section{Figura 2}

Imagem ilustrativa da superfície do pavimento da ciclovia rígido, do trecho da Esplanada dos Ministérios, produzido em concreto simples, com juntas cortadas e espaçadas a cada $3 \mathrm{~m}$ 
selecionado para aplicação da metodologia foi a ciclovia localizada na região da Esplanada dos Ministérios em Brasília-DF (Figura 1).

Conforme apresentado na Figura 1, a ciclovia fica situada na área central de Brasília-DF, no canteiro central do Eixo Monumental, via que corta o Plano Piloto no sentido Leste-Oeste, e serve de ligação entre a Rodoviária do Plano Piloto e o Congresso Nacional, passando pela Biblioteca Nacional de Brasília, Museu Nacional da República Honestino Guimarães, Catedral Metropolitana Nossa Senhora Aparecida (Catedral de Brasília), prédios dos ministérios (Esplanada dos Ministérios) e o Teatro Nacional Cláudio Santoro.

Esse trecho de ciclovia está localizado em uma região com elevado potencial para o uso da bicicleta devido ao relevo plano, ao grande número de postos de trabalho ligados à administração pública federal e ao potencial turístico. Além disso, existe uma facilidade de integração da ciclovia com a Rodoviária do Plano Piloto, principal terminal de linhas de ônibus urbanas e metropolitanas, e a estação terminal das duas linhas existentes do metrô do Distrito Federal.

\section{I Descrição da amostra}

As informações necessárias para caracterizar a ciclovia foram obtidas com a Companhia Urbanizadora da Nova Capital (NOVACAP), órgão responsável pela construção da ciclovia. Um resumo desses dados está reunido na Tabela 2.

Não há informações específicas sobre o concreto utilizado no pavimento da ciclovia, como o traço, que traria as quantidades de cada um dos seus componentes, e os materiais constituintes. A única informação conhecida é a resistência à compressão especificada no projeto como sendo de $18 \mathrm{MPa}$, aos 28 dias. O pavimento é dividido em placas, separados por juntas equidistantes a cada $3,00 \mathrm{~m}$. A ciclovia tem 2,50 m de largura. A Figura 2 apresenta uma

Tabela 3 - Resumo do inventário para a etapa de obtenção dos materiais (cont.)

\begin{tabular}{|c|c|c|c|c|}
\hline $\begin{array}{l}\text { Processo } \\
\text { principal }\end{array}$ & Tipo de Fluxo & Fluxo & Quantidade & Unidade \\
\hline \multirow{7}{*}{$\begin{array}{l}\text { Areia } \\
(1 \mathrm{~kg})\end{array}$} & Material & Areia de quartzo & 1 & $\mathrm{~kg}$ \\
\hline & \multirow{2}{*}{ Solo } & Ocupação & 0,015476 & $\mathrm{~m}^{2} \cdot \mathrm{a}$ \\
\hline & & Área de extração & $1,55 \mathrm{E}-04$ & $\mathrm{~m}^{2}$ \\
\hline & \multirow{2}{*}{ Energia } & Eletricidade & $1,30 \mathrm{E}-04$ & kWh \\
\hline & & Óleo diesel & 0,049911 & MJ \\
\hline & \multirow{2}{*}{ Emissões } & Água lançada no ar & $1,50 \mathrm{E}-04$ & $\mathrm{~m}^{3}$ \\
\hline & & Água lançada na água & $8,00 \mathrm{E}-03$ & $\mathrm{~m}^{3}$ \\
\hline \multirow{13}{*}{$\begin{array}{l}\text { Pedra britada } \\
\qquad(1 \mathrm{~kg})\end{array}$} & \multirow{2}{*}{ Material } & Granito & 1 & $\mathrm{~kg}$ \\
\hline & & Água & 0,0205 & $\mathrm{~kg}$ \\
\hline & \multirow{3}{*}{ Solo } & Ocupação de lago & $9,824 \mathrm{E}-6$ & $m^{2} \cdot a$ \\
\hline & & $\begin{array}{l}\text { Ocupação local de } \\
\text { extração mineral }\end{array}$ & 2,358E-04 & $\mathrm{m}^{2} \cdot \mathrm{a}$ \\
\hline & & Área de extração & 2,947E-06 & $\mathrm{m}^{2}$ \\
\hline & \multirow{4}{*}{ Energia } & Explosivo & $3,7 \mathrm{E}-04$ & $\mathrm{~kg}$ \\
\hline & & Diesel & 0,027216 & MJ \\
\hline & & Eletricidade & 2,74E-03 & kWh \\
\hline & & Óleo lubrificante & $8,56 \mathrm{E}-06$ & $\mathrm{~kg}$ \\
\hline & \multirow{4}{*}{ Emissões } & Partículas $<2.5 \mu \mathrm{m}$ & $2,1 \mathrm{E}-7$ & $\mathrm{~kg}$ \\
\hline & & Partículas $>10 \mu \mathrm{m}$ & $2,716 \mathrm{E}-06$ & $\mathrm{~kg}$ \\
\hline & & $\begin{array}{c}\text { Partículas entre } 2,5 \mu \mathrm{m} \\
\text { e } 10 \mu \mathrm{m}\end{array}$ & $2,78 \mathrm{E}-06$ & $\mathrm{~kg}$ \\
\hline & & Água & $2,05 E-05$ & $\mathrm{~kg}$ \\
\hline \multirow{7}{*}{$\begin{array}{l}\text { Concreto usinado } \\
\left(1 \mathrm{~m}^{3}\right) 20 \mathrm{MPa}\end{array}$} & \multirow{5}{*}{ Materiais } & Cimento - CP II F-32 & 309 & $\mathrm{~kg}$ \\
\hline & & Areia & 766,32 & $\mathrm{~kg}$ \\
\hline & & Brita & 1149,5 & $\mathrm{~kg}$ \\
\hline & & Água & 262,65 & $\mathrm{~kg}$ \\
\hline & & Aditivo superplastificante & 2,2915 & $\mathrm{~kg}$ \\
\hline & Energia & Eletricidade & 3,0797 & kWh \\
\hline & Emissão & Água para 0 ar & 0,03708 & $\mathrm{~m}^{3}$ \\
\hline
\end{tabular}


Tabela 4 - Resumo do inventário para o cimento e clínquer da Ecoinvent

\begin{tabular}{|c|c|c|c|c|}
\hline $\begin{array}{l}\text { Processo } \\
\text { principal }\end{array}$ & Tipo de Fluxo & Fluxo & Quantidade & Unidade \\
\hline \multirow{14}{*}{$\begin{array}{l}\text { Cimento } \\
(1 \mathrm{~kg}) \\
\mathrm{CP} \| \mathrm{F}-32\end{array}$} & \multirow{9}{*}{ Materiais } & Clínquer & 0,86 & $\mathrm{~kg}$ \\
\hline & & Gesso & 0,05 & $\mathrm{~kg}$ \\
\hline & & Fíler calcário & 0,09 & $\mathrm{~kg}$ \\
\hline & & Dietilenoglicol & $5,3 \mathrm{E}-04$ & $\mathrm{~kg}$ \\
\hline & & Água da chuva & 3,97E-03 & $\mathrm{kg}$ \\
\hline & & Água da torneira & $1,45 \mathrm{E}-03$ & $\mathrm{~kg}$ \\
\hline & & Água do rio & $1,24 \mathrm{E}-04$ & $m^{3}$ \\
\hline & & Água de origem natural & $2,03 \mathrm{E}-06$ & $m^{3}$ \\
\hline & & Água de poço & $5,65 E-05$ & $\mathrm{~m}^{3}$ \\
\hline & \multirow{2}{*}{$\begin{array}{l}\text { Recursos } \\
\text { industriais }\end{array}$} & Borracha sintética & $8,8 \mathrm{E}-06$ & $\mathrm{~kg}$ \\
\hline & & Óleo lubrificante & $5,5 \mathrm{E}-06$ & $\mathrm{~kg}$ \\
\hline & \multirow{2}{*}{ Energia } & Eletricidade & 0,051 & kWh \\
\hline & & Gás natural & 0,02053 & MJ \\
\hline & Emissões & Água & $1,87 \mathrm{E}-04$ & $\mathrm{~kg}$ \\
\hline \multirow{26}{*}{$\begin{array}{l}\text { Clínquer } \\
\text { (1 kg) }\end{array}$} & \multirow{14}{*}{ Materiais } & Argila & 0,12 & $\mathrm{~kg}$ \\
\hline & & Bauxita & 0,0106 & $\mathrm{~kg}$ \\
\hline & & Minério de ferro & 0,0048 & $\mathrm{~kg}$ \\
\hline & & Fíler calcário & 1,42 & $\mathrm{~kg}$ \\
\hline & & Escória de alto forno & $1,46 \mathrm{E}-03$ & $\mathrm{~kg}$ \\
\hline & & Areia & $8,34 \mathrm{E}-03$ & $\mathrm{~kg}$ \\
\hline & & Brita & 0,074 & $\mathrm{~kg}$ \\
\hline & & Xisto & 0,0107 & $\mathrm{~kg}$ \\
\hline & & Ureia & $1,98 \mathrm{E}-04$ & $\mathrm{~kg}$ \\
\hline & & Água da chuva & $5,38 \mathrm{E}-03$ & $\mathrm{~kg}$ \\
\hline & & Água da torneira & $1,92 \mathrm{E}-03$ & $\mathrm{~kg}$ \\
\hline & & Água do rio & $1,66 \mathrm{E}-04$ & $\mathrm{~m}^{3}$ \\
\hline & & Água de origem natural & $2,78 \mathrm{E}-06$ & $m^{3}$ \\
\hline & & Água de poço & $7,46 \mathrm{E}-05$ & $\mathrm{~m}^{3}$ \\
\hline & \multirow{4}{*}{$\begin{array}{l}\text { Recursos } \\
\text { industriais }\end{array}$} & $\begin{array}{c}\text { Bobina de aço laminado } \\
\text { a quente }\end{array}$ & $1,11 \mathrm{E}-04$ & $\mathrm{~kg}$ \\
\hline & & Borracha sintética & $2,06 \mathrm{E}-05$ & $\mathrm{~kg}$ \\
\hline & & Óleo lubrificante & $1,07 \mathrm{E}-05$ & $\mathrm{~kg}$ \\
\hline & & Refratário & $2,93 \mathrm{E}-04$ & $\mathrm{~kg}$ \\
\hline & \multirow{8}{*}{ Energia } & Carvão & $8,19 \mathrm{E}-03$ & $\mathrm{~kg}$ \\
\hline & & Diesel & $9,67 \mathrm{E}-05$ & $\mathrm{~kg}$ \\
\hline & & Eletricidade & 0,077 & kWh \\
\hline & & Lenha (15 MJ/kg) & $2,74 \mathrm{E}-04$ & MJ \\
\hline & & Lignite & $6,92 \mathrm{E}-04$ & $\mathrm{~kg}$ \\
\hline & & Óleo combustível pesado & $1,48 \mathrm{E}-04$ & $\mathrm{~kg}$ \\
\hline & & Coque de petróleo & 0,089 & $\mathrm{~kg}$ \\
\hline & & Gás natural (36 MJ/m³) & $9,81 \mathrm{E}-06$ & $\mathrm{~m}^{3}$ \\
\hline
\end{tabular}

especificado e utilizado na produção dos concretos destinados a pavimentação rígida de ciclovias de Brasília, adotou-se o cimento Portland composto com adição de fíler (CP II F-32) no inventário. Os cimentos Portland do tipo II se destinam a aplicações gerais, sendo os mais encontrados no mercado nacional (>60\%) e os mais consumidos. Também, são recomendados pela Associação Brasileira de Cimento Portland (ABCP) como um dos mais adequados para aplicação em pavimentos de concreto.

Em 2013, ano de construção da ciclovia, a norma vigente para o cimento do tipo CP II-F era a ABNT NBR 11578:1991, que determinava o teor de adição entre $6 \%$ e 10\% para o fíler calcário e o restante de clínquer com sulfato de cálcio. Cabe ressaltar que atualmente o teor máximo de substituição passou para 25\%, conforme a ABNT NBR 16697:2018. No inventário desse estudo, adotou-se para esse cimento a maior porcentagem de filer (10\%), conforme norma vigente no período da execução da ciclovia, e as quantidades adotadas de cada componente do clínquer foram retiradas da base de dados do SICV Brasil. As fontes energéticas da indústria cimenteira e as emissões foram calculadas pela metodologia utilizada por Vieira et al. [8].

$\mathrm{Na}$ produção de concreto usinado no Distrito Federal, utiliza-se comumente a areia britada ou pó de pedra, como agregado miúdo. O banco de dados da SICV Brasil não apresenta dados sobre nenhum deles. Por isso, foi necessário recorrer aos dados do inventário da Ecoinvent, que apresenta o processo de 
areia britada com dados brasileiros, adotado nesse estudo. Da mesma forma, o agregado graúdo também não consta no SICV Brasil, sendo necessário selecionar dados provenientes do inventário da Ecoinvent de pedra britada com produção brasileira.

Por falta de informações específicas sobre o concreto utilizado, adotou-se o inventário do concreto da Ecoinvent que contém todos os insumos citados anteriormente juntamente com a água e aditivo. Os quantitativos desses constituintes, a energia e as emissões foram constituídos com base no concreto de $20 \mathrm{MPa}$, resistência mais próxima da especificada no projeto do pavimento rígido. A Tabela 3 apresenta um resumo do inventário dos materiais.

Também foi feita uma análise com os fluxos do cimento CP || F-32 retirados do inventário da Ecoinvent, tornando possível comparar os resultados com os do inventário do SICV Brasil. A Tabela 4 traz os fluxos do cimento e do clínquer do inventário da Ecoinvent.

\subsection{Resultados da avaliação de Ciclo de Vida}

Os valores dos impactos gerados na produção de cada um dos constituintes do concreto que compõe a camada de pavimento rígido por metro quadrado com o inventário do cimento da SICV Brasil estão apresentados na Tabela 5.

A Figura 3 apresenta a contribuição, em percentual, de cada insumo por categoria de impacto.

Os resultados obtidos mostram que o cimento é o material constituinte do concreto que mais impacta em todas as categorias analisadas.
Esse resultado acontece por conta dos combustíveis utilizados na produção do clínquer (principal componente do cimento Portland) que liberam diversos poluentes na atmosfera, em especial o dióxido de carbono $\left(\mathrm{CO}_{2}\right)$.

Em segundo lugar, aparece o agregado graúdo, com contribuições inferiores a $4 \%$ em quase todas as categorias. Os valores excedentes a esse
> Tabela 4 - Resumo do inventário para o cimento e clínquer da Ecoinvent (cont.)

\begin{tabular}{|c|c|c|c|c|}
\hline $\begin{array}{l}\text { Processo } \\
\text { principal }\end{array}$ & Tipo de Fluxo & Fluxo & Quantidade & Unidade \\
\hline \multirow{29}{*}{$\begin{array}{l}\text { Clínquer } \\
\text { (1 kg) }\end{array}$} & \multirow{29}{*}{ Emissões } & Antimônio & $8,48 \mathrm{E}-09$ & $\mathrm{~kg}$ \\
\hline & & Arsênio & 8,93E-09 & $\mathrm{kg}$ \\
\hline & & Berílio & $8,27 \mathrm{E}-09$ & $\mathrm{~kg}$ \\
\hline & & Cádmio & $5,74 \mathrm{E}-09$ & $\mathrm{~kg}$ \\
\hline & & $\begin{array}{l}\text { Dióxido de carbono, } \\
\text { fóssil }\end{array}$ & 0,832 & $\mathrm{~kg}$ \\
\hline & & $\begin{array}{c}\text { Dióxido de carbono, não } \\
\text { fóssil }\end{array}$ & 0,031 & $\mathrm{~kg}$ \\
\hline & & $\begin{array}{l}\text { Monóxido de carbono, } \\
\text { fóssil }\end{array}$ & $7,66 \mathrm{E}-04$ & $\mathrm{~kg}$ \\
\hline & & Cromo & $3,91 \mathrm{E}-07$ & $\mathrm{~kg}$ \\
\hline & & Cobalto & $1,23 \mathrm{E}-08$ & $\mathrm{~kg}$ \\
\hline & & Cobre & $9,07 \mathrm{E}-08$ & $\mathrm{~kg}$ \\
\hline & & $\begin{array}{c}\text { Dioxinas, medidas } \\
\text { como 2,3,7,8-tetraclorodi- } \\
\text { benzo-p-dioxina }\end{array}$ & $7,18 \mathrm{E}-14$ & $\mathrm{~kg}$ \\
\hline & & $\begin{array}{l}\text { Hidrocarbonetos, } \\
\text { não especificados }\end{array}$ & $1,85 \mathrm{E}-05$ & $\mathrm{~kg}$ \\
\hline & & Cloreto de hidrogênio & $5,48 \mathrm{E}-06$ & $\mathrm{~kg}$ \\
\hline & & Fluoreto de hidrogênio & $7,97 \mathrm{E}-07$ & $\mathrm{~kg}$ \\
\hline & & Chumbo & $8,71 \mathrm{E}-08$ & $\mathrm{~kg}$ \\
\hline & & Manganês & $8,19 \mathrm{E}-07$ & $\mathrm{~kg}$ \\
\hline & & Mercúrio & $4,62 \mathrm{E}-09$ & $\mathrm{~kg}$ \\
\hline & & Níquel & $2,88 \mathrm{E}-07$ & $\mathrm{~kg}$ \\
\hline & & Óxidos de nitrogênio & 2,27E-03 & $\mathrm{kg}$ \\
\hline & & Partículas $<2.5 \mu \mathrm{m}$ & $2,7 \mathrm{E}-05$ & $\mathrm{~kg}$ \\
\hline & & Partículas $>10 \mu \mathrm{m}$ & $1,93 \mathrm{E}-05$ & $\mathrm{~kg}$ \\
\hline & & $\begin{array}{l}\text { Partículas entre } 2,5 \mu \mathrm{m} \\
\text { e } 10 \mu \mathrm{m}\end{array}$ & 8,22E-05 & $\mathrm{kg}$ \\
\hline & & Selênio & $1,2 \mathrm{E}-08$ & $\mathrm{~kg}$ \\
\hline & & Óxidos de enxofre & $9,16 \mathrm{E}-04$ & $\mathrm{~kg}$ \\
\hline & & Tálio & $8,64 \mathrm{E}-09$ & $\mathrm{~kg}$ \\
\hline & & Estanho & $2,34 \mathrm{E}-07$ & $\mathrm{~kg}$ \\
\hline & & Água residual & $1,92 \mathrm{E}-06$ & $\mathrm{~m}^{3}$ \\
\hline & & Água & $2,49 \mathrm{E}-04$ & $m^{3}$ \\
\hline & & Zinco & $2,18 \mathrm{E}-06$ & $\mathrm{~kg}$ \\
\hline
\end{tabular}


Tabela 5 - Valores obtidos para as categorias de impacto de cada constituinte do concreto por $\mathrm{m}^{2}$ com inventário do cimento da SICV Brasil

\begin{tabular}{|c|c|c|c|c|c|}
\hline Categorias de impacto (sigla) - unidade & Cimento & $\begin{array}{l}\text { Agregado } \\
\text { graúdo }\end{array}$ & $\begin{array}{l}\text { Agregado } \\
\text { miúdo }\end{array}$ & Água & Aditivo \\
\hline Potencial de depleção abiótica (ADP) - kg antimony - Eq & 2,19E-05 & $9,23 \mathrm{E}-07$ & 5,63E-09 & 5,93E-09 & $4,31 \mathrm{E}-08$ \\
\hline Potencial de acidificação (AP) - $\mathrm{kg} \mathrm{SO}_{2}$ - Eq & $2,79 \mathrm{E}+01$ & 2,81E-02 & 1,33E-04 & $1,39 \mathrm{E}-04$ & $3,39 \mathrm{E}-03$ \\
\hline Potencial de aquecimento global (GWP) $-\mathrm{kg} \mathrm{CO}_{2}$ - Eq & $3,67 \mathrm{E}+01$ & $5,10 \mathrm{E}-02$ & $1,29 \mathrm{E}-04$ & $1,36 \mathrm{E}-04$ & $6,71 \mathrm{E}-01$ \\
\hline Potencial de eutrofização $(E P)-\mathrm{kg} \mathrm{PO}_{4}$ - Eq & $2,11 \mathrm{E}-02$ & $4,42 \mathrm{E}-03$ & $1,72 \mathrm{E}-06$ & $1,81 \mathrm{E}-06$ & $3,34 \mathrm{E}-04$ \\
\hline Potencial de ecotoxicidade de águas doces (FAETP) - kg 1,4 - DCB - Eq & $1,90 \mathrm{E}-01$ & $2,74 \mathrm{E}-03$ & $5,61 \mathrm{E}-05$ & $5,90 \mathrm{E}-05$ & $1,22 \mathrm{E}-02$ \\
\hline Potencial de toxicidade humana (HTP) - kg 1,4 - DCB - Eq & $1,47 \mathrm{E}+01$ & 2,69E-01 & 6,87E-03 & 7,17E-03 & $6,00 \mathrm{E}-02$ \\
\hline Potencial de ecotoxicidade de águas marinhas (MAETP) - kg 1,4 - DCB - Eq & $8,21 \mathrm{E}+03$ & $1,97 \mathrm{E}+02$ & $5,76 \mathrm{E}+00$ & $6,06 \mathrm{E}+00$ & $1,69 \mathrm{E}+02$ \\
\hline Potencial de criação de ozônio fotoquímico (POCP) - kg ethylene - Eq & $1,37 \mathrm{E}+00$ & $3,95 \mathrm{E}-04$ & $6,82 \mathrm{E}-06$ & $7,18 \mathrm{E}-06$ & $1,66 \mathrm{E}-04$ \\
\hline Potencial de depleção de ozônio (ODP) - kg CFC - 11 - Eq & $3,41 \mathrm{E}-06$ & $7,62 \mathrm{E}-08$ & 2,21E-09 & 2,32E-09 & $2,26 \mathrm{E}-08$ \\
\hline Potencial de ecotoxicidade terrestre (TAETP) - kg 1,4 - DCB Eq & $2,16 \mathrm{E}-01$ & $2,18 \mathrm{E}-03$ & $5,50 \mathrm{E}-05$ & $5,84 \mathrm{E}-05$ & $2,10 \mathrm{E}-03$ \\
\hline
\end{tabular}

patamar aparecem nas categorias de ADP e EP, com 4,04\% e 17,10\%, respectivamente, e destacam-se por conta da forma de extração desse material.

As menores contribuições ficam com o agregado miúdo, a água de amassamento e o aditivo. A areia também apresenta pouca interferência nas categorias, pois é utilizada praticamente da forma como é extraída. Já, o aditivo acaba tendo pouca influência devido à pequena quantidade utilizada quando comparado aos outros materiais constituintes.

Após a análise dos materiais utilizados na produção do concreto para a ciclovia, é possível estudar a possibilidade de substituição dos materiais tradicionais por alternativos que sejam menos poluentes.

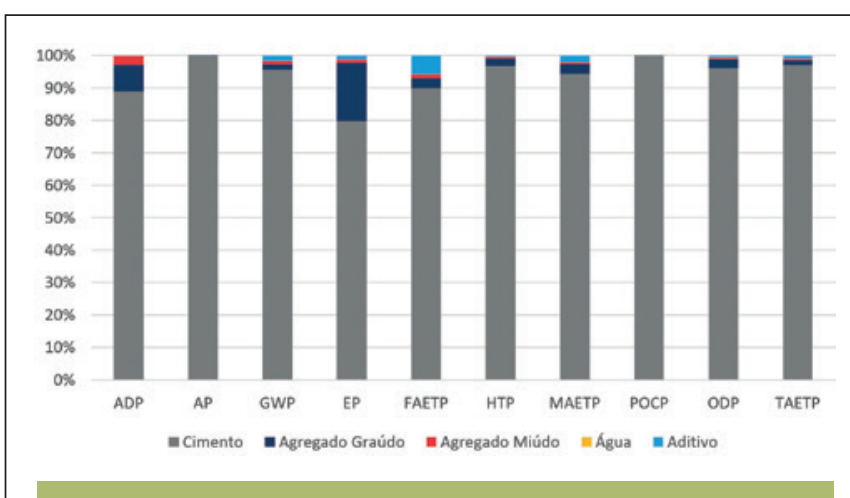

Figura 3

Contribuição, em percentual, de cada insumo utilizado na produção do concreto para o pavimento de ciclovia, por categoria de impacto
Tabela 6 - Comparação entre os valores obtidos para as categorias de impacto do cimento da base de dados do SICV Brasil e da Ecoinvent

\begin{tabular}{|c|c|c|}
\hline Categorias de impacto (sigla) - unidade & $\begin{array}{c}\text { Cimento } \\
\text { SICV } \\
\text { Brasil }\end{array}$ & $\begin{array}{l}\text { Cimento } \\
\text { Ecoinvent }\end{array}$ \\
\hline $\begin{array}{l}\text { Potencial de depleção abiótica } \\
\text { (ADP) - kg antimony - Eq }\end{array}$ & 2,19E-05 & $2,14 \mathrm{E}-05$ \\
\hline Potencial de acidificação (AP) - $\mathrm{kg} \mathrm{SO}_{2}$ - Eq & $2,79 \mathrm{E}+01$ & $1,06 \mathrm{E}-01$ \\
\hline $\begin{array}{l}\text { Potencial de aquecimento } \\
\text { global (GWP) }-\mathrm{kg} \mathrm{CO}_{2}-\mathrm{Eq}\end{array}$ & $3,67 \mathrm{E}+01$ & $1,85 \mathrm{E}+01$ \\
\hline Potencial de eutrofização (EP) - $\mathrm{kg} \mathrm{PO}_{4}$ - Eq & 2,11E-02 & 7,09E-03 \\
\hline $\begin{array}{l}\text { Potencial de ecotoxicidade de águas } \\
\text { doces (FAETP) - kg 1,4 - DCB - Eq }\end{array}$ & $1,90 \mathrm{E}-01$ & 3,83E-02 \\
\hline $\begin{array}{c}\text { Potencial de toxicidade } \\
\text { humana (HTP) - kg 1,4 - DCB - Eq }\end{array}$ & $1,47 \mathrm{E}+01$ & $3,23 \mathrm{E}+00$ \\
\hline $\begin{array}{l}\text { Potencial de ecotoxicidade de águas } \\
\text { marinhas (MAETP) - kg 1,4 - DCB - Eq }\end{array}$ & $8,21 \mathrm{E}+03$ & $3,03 \mathrm{E}+03$ \\
\hline $\begin{array}{l}\text { Potencial de criação de ozônio } \\
\text { fotoquímico (POCP) - kg ethylene - Eq }\end{array}$ & $1,37 \mathrm{E}+00$ & 4,66E-02 \\
\hline $\begin{array}{l}\text { Potencial de depleção de ozônio (ODP) - } \\
\text { kg CFC - } 11 \text { - Eq }\end{array}$ & $3,41 \mathrm{E}-06$ & $8,12 \mathrm{E}-07$ \\
\hline $\begin{array}{l}\text { Potencial de ecotoxicidade terrestre } \\
\text { (TAETP) - kg 1,4 - DCB - Eq }\end{array}$ & $2,16 \mathrm{E}-01$ & $2,73 \mathrm{E}-02$ \\
\hline
\end{tabular}


do cimento por algum outro com menor quantidade de clínquer e maior de MCS (materiais cimentícios suplementares). Como o cimento é o maior contribuinte nos impactos analisados, essa troca reduziria os valores dos impactos causados.

Outra possibilidade seria o emprego de agregados reciclados de concreto. Porém, é importante analisar se os impactos causados pelos processos adotados para a transformação dos resíduos em agregado reciclado seriam menores que os impactos pelo uso do agregado graúdo já comumente utilizado.

Por fim, foi realizada uma comparação entre os inventários do cimento da base de dados brasileira e da Ecoinvent. Os valores estão apresentados na Tabela 6.

Nota-se que, ao utilizar os valores do inventário da Ecoinvent, os impactos são menores do que quando se utiliza o inventário do SICV Brasil. As composições de inventário possuem diferenças significativas tanto nos recursos e nas energias de entrada quanto nas emissões que são as saídas do processo. Portanto, a escolha da base de dados pode trazer resultados diferentes.

Após examinar todos esses resul- tados, é importante ressaltar a necessidade de definir outros indicadores além das categorias de impacto analisadas. Esses indicadores estariam mais relacionados à construção civil, como consumo de materiais, geração de resíduos, consumo de água e de energia.

\section{CONCLUSÕES}

A ACV se revelou como uma atividade complexa pelo grande número de informações de entrada e ausência de dados brasileiros. Mesmo assim, ela trouxe resultados importantes sobre os materiais que compõem o sistema de pavimento rígido e pode auxiliar nas tomadas de decisões em futuros projetos desse tipo de estrutura.

A principal dificuldade para a montagem do inventário de ACV foi a falta de informações disponíveis sobre os materiais utilizados na produção do concreto das ciclovias do Distrito Federal.

Nos estudos de ACV pesquisados, a camada de pavimento rígido é a maior contribuinte para os impactos ambientais. Dentre os materiais constituintes dessa camada, conforme foi constatado, o cimento traz as maiores contribuições nas ca- tegorias analisadas. Isso aconteceu principalmente pelos combustíveis utilizados na produção do clínquer, principal componente do cimento. A comparação do cimento com dados retirados de diferentes inventários trouxe resultados com diferenças significativas, demonstrando que a escolha da base de dados pode modificar os resultados.

Por isso, a recomendação para uso de cimentos com menor quantidade de clínquer em sua composição pode ajudar a reduzir os impactos mensurados. Outra possibilidade levantada seria a utilização de agregados reciclados de concreto, que deve ser avaliada como alternativa viável na mitigação dos danos avaliados.

Por fim, observa-se a necessidade de definir novos indicadores relacionados à construção civil (consumo de materiais, geração de resíduos, consumo de água e de energia, por exemplo), que auxiliariam na tomada de decisão em futuros projetos de ciclovia.

\section{AGRADECIMENTOS}

Ao CNPq, pelo apoio recebido durante o desenvolvimento desta pesquisa.

\section{DREFERENCIAS BIBLIOGRÁFICAS}

[1] ASSOCIAÇÃO BRASILEIRA DE NORMAS TÉCNICAS. ABNT NBR ISO 14040: Gestão ambiental - Avaliação do ciclo de vida - Princípios e estrutura. Rio de Janeiro, 2009 .

[2] SICV BRASIL. Banco Nacional de Inventários do Ciclo de Vida. Disponível em: <https://sicv.ibict.br/Node/>. Acesso em: 7 de Maio de 2021.

[3] ECOINVENT. The life cycle inventory data version 3.6. SwissCentre for Life Cycle Inventories, 2019. Disponível em <https://ecoquery.ecoinvent.org/>. Acesso em 11 de Maio de 2021.

[4] GREENDELTA. OpenLCA. GreenDelta, Berlin, v.1.10.2, 2019.

[5] MENDOZA, J. M. F; OLIVER-SOLÀ, J.; GABARRELL, X.; JOSA, A.; RIERADEVALL, J. Life cycle assessment of granite application in sidewalks. International Journal of Life Cycle Assessment, v. 17, n. 5, p. 580-592, 2012.

[6] OLIVER-SOLÀ, J.; ROSI, A.; RIERADEVALL, J.; GABARRELL, X. Environmental optimization of concrete sidewalks in urban areas. International Journal of Life Cycle Assessment, v. 14, n. 4, p. 302-312, 2009.

[7] BOZORG CHENANI, S.; LEHVÄVIRTA, S.; HÄKKINEN, T. Life cycle assessment of layers of green roofs. Journal of Cleaner Production, v. 90, p. 153-162, 2015.

[8] VIEIRA, D. R.; CALMON, J. L.; ZULCÃO, R.; COELHO, F. Z. Consideration of strength and service life in cradle-to-gate life cycle assessment of self-compacting concrete in a maritime area: a study in the Brazilian context. Environment, Development and Sustainability, v. 20, n. 4, p. 1849-1871, 2017. 